\title{
$O$ uso de estrangeirismos em nomes de estabelecimentos comerciais na cidade de Arapongas (PR)
}

\author{
Marluce Fagotti de PAIVA (CAPES) \\ Ismael PONTES \\ Universidade Estadual de Londrina \\ Amanda Staub MERCURIO \\ Andréia Cristina de MORAES \\ Juliana TREVISOLI \\ Luciene Paula de CAMARGO \\ Universidade Norte do Paraná
}

Palavras-chave: estrangeirismos; comércios; aspectos lingüísticos e sócioculturais.

Resumo: Neste trabalho, fazemos uma descrição preliminar de aspectos lingüísticos e sócio-culturais dos estrangeirismos na denominação de estabelecimentos comerciais na cidade de Arapongas, região norte do Paraná.

Abstract: This paper, we aim to present a description of Brazilian shop owners and the English words found on the names of their commerce in Arapongas city, north of Paraná.

Resumen: Neste trabajo, haciemos una descrición de los aspectos lingüísticos y socio-culturais de los extranjerismos en la denominación de esteblecimientos comerciales en la ciudad de Arapongas, región norte del Paraná.

SIGNUM: Estud. Ling., Londrina, n. 5, p. 227-237, dez. 2002 


\section{Introdução}

Que a língua é dinâmica e está sempre em processo de mudança parece óbvio até mesmo para aqueles que se iniciam em estudos da linguagem; no entanto, essa dinâmica das línguas naturais parece, às vezes, ser esquecida. Um exemplo bem típico desse esquecimento encontramos no projeto de lei do deputado Aldo Rebelo, com o qual ele propõe substituir termos estrangeiros por equivalentes em português (Rebelo, 1999). Tentativas como essa de interromper o curso natural das línguas - se isso é possível - evidenciam a pouca importância com que a língua tem sido tratada por aqueles que, embora tenham muitas vezes o poder de sobre ela tomar decisões, têm uma compreensão leiga da realidade lingüística tal como se apresenta no seio da sociedade. Todavia, é preciso reconhecer que o projeto do deputado Rebelo despertou importantes discussões entre lingüistas e os adeptos de um conservadorismo equivocado sobre a língua portuguesa. Do lado dos lingüistas, têm sido muitas as contribuições tanto no sentido de chamar a atenção da comunidade acadêmica sobre o uso cotidiano da língua nas comunidades de fala quanto no sentido de provocar reflexões mais profundas sobre a relação língua e sociedade.

Neste trabalho, tendo em vista nosso interesse em compreender a dinâmica dos estrangeirismos na língua portuguesa, buscamos descrever preliminarmente alguns aspectos lingüísticos e sócio-culturais depreendidos em termos estrangeiros usados por falantes da variedade lingüística norte paranaense em denominações de estabelecimentos comerciais.

\section{A polêmica em torno dos estrangeirismos}

O livro Estrangeirismos: guerra em torno da língua do professor Carlos Alberto Faraco, que contém uma coletânea de artigos posicionando-se a respeito do projeto de lei sobre os estrangeirismos, parece mostrar claramente a importância das pesquisas lingüísticas e dos estudiosos da 
língua no que concerne às questões de política de linguagem. O projeto do deputado Rebelo, ao ser divulgado pela mídia, obteve a simpatia de muitas pessoas que concordam em proteger a língua e a grande maioria dos brasileiros que desconhecem o inglês. $O$ deputado levanta a velha questão do nacionalismo, da proteção do mais fraco diante do mais forte. Aparentemente, a solução seria a unificação das classes sociais por intermédio da linguagem. Por outro lado, os lingüistas vêem com descrença a proposta de Rebelo: pois o projeto, além de não apresentar uma fundamentação científica que justifique a restrição ao uso de palavras estrangeiras, não leva em conta as condições lingüísticas, históricas e sócioculturais em que tais termos estão se inserindo na língua portuguesa.

Certamente, décadas de pesquisa lingüística no Brasil e fatos históricos seriam totalmente desconsiderados com a aprovação desse projeto. A língua é resultado do pensamento do povo, da sua interação na sociedade, seria possível, então, proibi-lo de pensar? O projeto se baseia no danoso equívoco de que a língua padrão não se altera com o tempo, "ignora a heterogeneidade e a dinâmica da vida cultural, impondo o homogêneo e o único" (Faraco, 2001, p. 45). É preciso considerar que os estrangeirismos não fazem desaparecer termos do fundo léxico comum da língua (as preposições, as conjunções, os pronomes, os numerais, os advérbios, a maioria dos verbos e muitos adjetivos), interferindo mais diretamente apenas "no âmbito dos substantivos, pois denominam objetos e produtos que se renovam constantemente, ou noções abstratas que estão submetidas a mutações devidas à marcha da história" (Fiorin, 2001, p. 117).

Os estrangeirismos, na maioria das vezes, agregam um sentido não lingüístico, dessa maneira a linguagem aparece como instrumento para informar, expressar o pensamento, expressar intenções, agir. A respeito dos estrangeirismos devemos levar em consideração "o sentido como intenção do locutor", isto é "trata-se de um sujeito consciente de suas intenções, capaz de comunicá-las a alguém” (Guimarães, 1995). Desse modo, 
entendemos que o grande desafio não é proteger a língua dos estrangeirismos e de outros fenômenos lingüísticos que naturalmente afetam sua estrutura, mas compreender como esses fenômenos se inserem e qual a sua relevância para a estrutura da língua, bem como o status social que adquirem na interação entre os falantes de uma comunidade de fala. Nesse sentido, este trabalho não tem como objetivo propriamente se posicionar em relação à polêmica que se estabeleceu em torno dos estrangeirismos, mas compreender como os falantes da língua portuguesa (variedade lingüística norte paranaense) lidam com os termos estrangeiros. Para isso, tomamos como objeto de estudo os nomes de estabelecimentos comerciais, que constituem um campo do léxico em que os estrangeirismos aparecem freqüentemente e apresentam valor simbólico, social e comercial. Pois o nome de um estabelecimento é, de certa forma, o primeiro contato que o cliente tem com ele. É também, a nosso ver, a primeira impressão que se caracteriza daquele comércio e do produto por ele comercializado.

\section{Procedimentos metodológicos}

Os dados referentes aos nomes dos estabelecimentos comerciais, que constituem nosso corpus, foram coletados na cidade de Arapongas. Arapongas situa-se no norte do Paraná a 30 quilômetros de Londrina, possui cerca de 83 mil habitantes e tem 55 anos. A cidade tem apresentado um crescimento bem acentuado nos últimos anos devido à expansão da Universidade Norte do Paraná - UNOPAR - e, principalmente, à consolidação do comércio moveleiro: há duas grandes feiras do setor que expõem e trazem expositores de todo o Brasil e do exterior, sendo uma delas a maior da América Latina.

Utilizamos como instrumento de coleta de dados um questionário cujas perguntas buscam depreender a relação do proprietário/informante com o(s) termo(s) estrangeiro(s) que utiliza na denominação de seu negócio: tais como significado e origem do nome; se possível, os motivos 
que o levaram à escolha de um nome em inglês; a consciência lingüística e social que ele tem do emprego de estrangeirismos.

A lista telefônica local foi utilizada como referencial na seleção dos estabelecimentos comerciais cujos proprietários seriam selecionados como informantes ${ }^{1}$. Mapeamos 1.147 comércios locais, entre esses 161 (15\%) tinham nomes que caracterizavam estrangeirismos. Dos 161 comércios, 85 - que apresentam explicitamente relação com a língua inglesa - foram selecionados para nossa investigação. Devido à resistência dos proprietários em ser entrevistados, conseguimos realizar inquérito em 36 estabelecimentos.

\section{Alguns aspectos lingüísticos e sociais de termos estrangeiros em nomes de estabelecimentos comerciais}

O primeiro aspecto a ser considerado sobre o uso dos estrangeirismos na denominação de estabelecimentos comerciais é, a nosso ver, o prestígio social que os comerciantes vêem nos termos estrangeiros. Os dados mostram que mais da metade dos proprietários (52\%), que lançam mão desse recurso lingüístico na hora de dar nome ao seu negócio, acredita que podem diferenciá-lo dos outros e agregam ao estrangeirismo uma força. Afirmam que em determinados negócios o nome deve ser forte, caso contrário não é competitivo. Observando as respostas referentes ao motivo pelo qual o proprietário optou pelo nome em inglês, constatamos que quatro idéias bases fundamentam essa escolha (ver tabela 1).

\footnotetext{
${ }^{1}$ Como precisávamos definir previamente os estabelecimentos comerciais em que iríamos realizar as entrevistas, decidimos não considerar aqueles que não constavam na lista telefônica local.
}

SIGNUM: Estud. Ling., Londrina, n. 5, p. 227-237, dez. 2002 
Tabela 1 - Motivos que levam os comerciantes a usarem termos em inglês nos nomes de seus estabelecimentos

\begin{tabular}{l|c}
\hline \hline \multicolumn{1}{c|}{ Respostas } & Quantidade de estabelecimentos \\
\hline $\begin{array}{l}\text { a) harmonia, beleza, simpatia e } \\
\text { requinte }\end{array}$ & 7 \\
\hline b) para chamar atenção & 3 \\
\hline c) a palavra é positiva & 2 \\
\hline d) refere-se à língua inglesa & 7 \\
\hline Total & 19 \\
\hline \hline
\end{tabular}

Mesmo, às vezes, não tendo consciência de que estão absorvendo uma cultura lingüística externa, os falantes buscam no inglês a expressividade para os nomes de seus estabelecimentos. Nossos dados registram três modos, a nosso ver, menos conscientes de incorporação de elementos da língua inglesa usados pelos proprietários para realçar a denominação de seus comércios: o caso genitivo, a substituição da denominação da língua portuguesa pela correspondente em inglês e a inversão da ordem dos elementos que compõem a denominação.

O caso genitivo aparece freqüentemente nos nomes dos comércios caracterizado por diversas funções atribuídas pelos seus proprietários. $\mathrm{Na}$ maioria das vezes, os informantes estruturam os sintagmas em desacordo com a regra do inglês e com a do português e afirmam que o 's carrega consigo uma beleza e charme que não sabem dizer de onde vêm, mas acreditam ser bom. O caso genitivo, representado pelo 's refere-se ao possuído e possuidor e apresenta-se, dessa forma, alguém que possui + 's + o que ela possui (Susan's house $=$ casa da Susan). Somente 1 dos 7 informantes que utilizam esse recurso demonstrou ter conhecimento de que se trata de uma estrutura sintagmática da língua inglesa, o restante relacionou-o a várias situações do português (ver tabela 2 ). 
Tabela 2 - Uso do genitivo na denominação de nomes de estabelecimentos

\begin{tabular}{l|l}
\hline \hline \multicolumn{1}{c|}{ Uso do genitivo } & \multicolumn{1}{c}{ Nome } \\
\hline a) para indicar plural & $\begin{array}{l}\text { Vic's Cabeleireiros } \\
\text { (3 donos, 's é para dar o plural) }\end{array}$ \\
\hline b) para dar charme & $\begin{array}{l}\text { Kituty's } \\
\text { (é o nome de uma doceria) }\end{array}$ \\
\hline c) para ficar diferente & $\begin{array}{l}\text { Tok' Special } \\
\text { (perfumaria) }\end{array}$ \\
\hline d) para chamar atenção & $\begin{array}{l}\text { Degrau's } \\
\text { (projetos e execuções de obras }\end{array}$ \\
\hline e) Relação possuído/possuidor & $\begin{array}{l}\text { Caninu's Rações } \\
\text { (ração para cães) }\end{array}$ \\
\hline \hline
\end{tabular}

Como observamos na tabela 2 , embora muitos informantes não concebam o caso genitivo com 's como uma estrutura da língua inglesa, atribuem uma valoração positiva ao uso dessa estrutura. Logo, se essa forma sintagmática transmite um requinte, uma diferença, uma beleza, tais características podem sugerir uma adaptação do sintagma na língua portuguesa, o que o leva a "denotar outros valores semânticos e tornarse, conseqüentemente, polissêmico", como afirma Alves (1994) a respeito da integração de um item estrangeiro a uma língua receptora.

Outros informantes - $21 \%$ dos proprietários entrevistados utilizam-se da língua inglesa para substituir o que gostariam de dizer em português; ou seja, realizam uma tradução do nome de seu estabelecimento para o inglês, por exemplo, Bike house para Loja de bicicletas, Celular Home para Loja de celulares. Observamos que a força e o prestígio do inglês na denominação de estabelecimentos comerciais também aqui se sobressai.

Em relação à ordem dos elementos que compõem um nome comercial, notamos que muitos não optam pela seqüência padrão do 
português, determinado-determinante; isto é, primeiro o termo genérico, seguido do termo específico, por exemplo, Bicicletaria Rouxinol, Calçados Aracalce, Lojas Colombo. Nossos dados mostram que 211 estabelecimentos optaram pela ordem inversa - determinante-determinado - proveniente do inglês, por exemplo, Dettector Alarmes, Red Point Representações, Emilia Confecções; no entanto, essa ordem, segundo os informantes, não remete a nenhum outro idioma senão o português. Isso significa, a nosso ver, que a inversão dos elementos - uma estrutura característica da língua inglesa na denominação de nomes de estabelecimentos goza de grande prestígio entre os comerciantes - de alguns setores ${ }^{2}$-; no entanto, depreende-se nas respostas dos informantes que eles não têm consciência da absorção de uma estrutura lingüística estrangeira.

Também chamou-nos a atenção o fato de várias vezes os informantes afirmarem que a tradução do(s) termo(s) estrangeiro(s) não ficaria bem, não soa bem em português. Parece que ao informá-lo em inglês o significado é menos exposto, menos compreendido, o produto fica em segundo plano e o que prevalece é a referência agregada ao termo, se é estrangeiro é melhor. Um exemplo disso registramos em uma loja de rações. A incidência de nomes em inglês nos produtos vendidos na loja é alta, mas só após a entrevista os proprietários constataram esse dado. Os produtos veterinários têm esta característica de apresentar-se com um nome estrangeiro, mesmo sendo nacionais. Ambos os donos não consideraram positiva a descoberta, acharam um abuso; porém, quando sugerimos a tradução da ração exposta na prateleira de nome Big Boss para Grande Chefe, eles acharam que não ficaria bem. Depreendemos assim, novamente, a força e o prestígio dos estrangeirismos, mesmo no discurso daqueles que relutam em aceitá-los.

\footnotetext{
${ }^{2}$ É importante ressaltar que esse recurso lingüístico é encontrado em determinados tipos de comércio: constatamos que, se nas áreas de confecções e móveis há predominância da inversão, My baby Confecções, Monegatto Móveis; todavia, em comércios como serralherias, farmácias, bicicletarias, entre outros, não registramos nenhuma ocorrência dessa ordem dos elementos nos nomes dos estabelecimentos.
} 
Aparentemente o contrário aconteceu em uma loja de sons com nome em inglês: Audio System Sound Security. O proprietário se recusou a pronunciar os dois últimos vocábulos alegando que o nome agora era só Audio System, embora os quatro termos fossem encontrados na lista telefônica e na placa do seu estabelecimento. Então, ainda que o informante se sentisse constrangido ao admitir que usa um nome estrangeiro para seu negócio, demonstra também inconscientemente estar incorporando os termos estrangeirismos como formas lingüísticas de prestígio no universo lexical dos negócios.

\section{Considerações finais}

Embora esta análise constitua um primeiro passo no sentido de compreender como os falantes lidam com os estrangeirismos na sua linguagem cotidiana, de modo geral, confirma, por um lado, mais uma vez o que os estudiosos, há décadas, vêm afirmando: não podemos tomar a língua como um sistema homogêneo e estático e fora da sociedade que a utiliza cotidianamente, tal como parece propor o projeto do deputado Rebelo. Por outro lado, revela aspectos importantes da complexa relação que existem entre os fenômenos lingüísticos e a estrutura sócio-cultural da comunidade de fala estudada.

Assim, se, ao estudar os estrangeirismos, considerarmos as dimensões lexical e semântica, mas principalmente a dimensão sóciocultural, poderemos ter uma compreensão mais ampla e profunda desse fenômeno. Pois é na investigação da relação falante, língua e sociedade que vamos depreender a complexidade de valores que assumem os termos estrangeiros na linguagem do dia-a-dia.

No que tange à dimensão social dos estrangeirismos, o motivo apresentado pela maioria dos nossos informantes quanto a escolha do termo estrangeiro é ser diferente, e essa escolha não deixa de ser uma maneira de individualizar uma preferência (um objeto) e expô-la. Todavia, para 
Ducrot (apud Guimarães, 1995) "o objeto tem a sua objetividade constituída pelo fato de várias falas falarem desse objeto", nesse sentido os estrangeirismos se polemizam pois, além da intenção do proprietário ao denominar seu estabelecimento em inglês, a exteriorização do nome envolve vários discursos (dos clientes), podendo resultar, por conseqüência, em várias reações, como exemplo, a) o constrangimento do cliente em não entender o que está escrito e o constrangimento até mesmo por parte do proprietário ao pronunciar o nome do próprio estabelecimento em inglês; $b$ ) a intenção de seleção da clientela por parte do proprietário e o sentimento de exclusão por parte dos clientes; e muitas vezes c) o modismo do que está em inglês é melhor confrontado com o sentimento de inferioridade do que está em português.

Finalmente, lembramos que são sentimentos de exclusão, de constrangimento, de inferioridade, que o deputado pretende modificar por intermédio da legislação. Mas estas questões são somente lingüísticas? Isto é, todos os clientes estariam em todas as lojas se estas tivessem o nome em português? A seleção consciente ou inconsciente determinada pelos nossos informantes parece não ser somente lingüística, mas social. É adequado citar neste momento uma afirmação de Foucault (1996, p. 10) que ilustra a situação: "Por mais que o discurso seja aparentemente bem pouca coisa, as interdições que o atingem revelam logo, rapidamente, sua ligação com o desejo e com o poder". A história tem nos mostrado as infindáveis lutas de classes sociais, do querer ser melhor e diferente, ou de simplesmente buscar o conforto e a felicidade. Desse modo, "pessoas de uma comunidade podem atribuir valores diversos às identidades ligadas aos falantes de outras línguas e os valores associados a um estrangeirismo podem ser conflitantes dentro da comunidade que o utiliza. Muitas vezes agrega-se à língua inglesa valores positivos, aos quais desejam-se associar" (Garcez; Zilles, 2001). 


\section{Referências bibliográficas}

AGENDA LOCAL. Lista Telefônica de Arapongas. Londrina: Local Publicações, 2001.

ALVES, Ieda Maria. Neologismos. Criação lexical. São Paulo: Ática, 1994. (Série Princípios)

FARACO, Carlos Alberto. (Org.) Estrangeirismos: guerra em torno da língua. São Paulo: Parábola, 2001.

FIORIN, José Luiz. Considerações em torno do projeto de Lei n. 1676/ 99. In: FARACO, Carlos Alberto (Org.). Estrangeirismos: guerra em torno da língua. São Paulo: Parábola, 2001.

FOUCAULT, Michel. A Ordem do Discurso. 7. ed. São Paulo: Loyola, 1996.

GUIMARÃES, Eduardo. Os limites do Sentido. São Paulo: Pontes, 1995.

GARCEZ, Pedro M.; ZILLES, Ana Maria S. Estrangeirismos: desejos e ameaças. In: FARACO, Carlos Alberto (Org.) Estrangeirismos: guerra em torno da língua. São Paulo: Parábola, 2001.

REBELO, Aldo. Projeto de Lei no 1676, de 1999. Dispõe sobre a promoção, a proteção, a defesa e o uso da língua portuguesa e dá outras providências. Disponível em: <http://www.camara.gov.br/aldorebelo/>. Acesso em: 21 out. 2002.

SIGNUM: Estud. Ling., Londrina, n. 5, p. 227-237, dez. 2002 